\title{
Team-based innovations in primary care delivery in Quebec and timely physician follow-up after hospital discharge: a population-based cohort study
}

\author{
Bruno D. Riverin MSc, Patricia Li MD MSc, Ashley I. Naimi PhD, Mamadou Diop BSc, \\ Sylvie Provost MD MSc, Erin Strumpf PhD
}

\section{Abstract}

Background: Outpatient follow-up has been a key intervention point in addressing gaps in care after hospital discharge. We sought to estimate the association between enrolment in new team-based primary care practices and 30-day postdischarge physician follow-up among older patients and patients with chronic illnesses who were admitted to hospital in Quebec, Canada.

\begin{abstract}
Methods: Patients were selected into this cohort if a primary care physician enrolled them as a "vulnerable patient" between November 2002 and January 2005. Data for this analysis included province-wide health insurance claims for inpatient and outpatient services delivered between November 2002 and January 2009 in Quebec. The primary analysis examined time to the first outpatient postdischarge follow-up service provided by either a primary care physician or a medical specialist. We used marginal structural models to estimate adjusted rates of follow-up with a primary care physician or with a medical specialist by primary care delivery models.
\end{abstract}

Results: We extracted billing data for 312377 patients that represented 620656 index admissions for any cause from 2002 to 2009. Rates of 30-day follow-up were 374 visits to primary care physicians and 422 visits to medical specialists per 1000 discharges. Rates of primary care physician follow-up were similar across primary care delivery models, except for patients with very high morbidity; these patients had significantly higher rates of follow-up with a primary care physician if they were enrolled in team-based primary care practices (30-d rate difference [RD] 13.3 more follow-up visits per 1000 discharges, 95\% confidence interval [Cl] 6.8 to 19.8 ). Rates of follow-up with a medical specialist were lower among patients enrolled in team-based practices, particularly within 15 days of hospital discharge (15-d RD 25.1 fewer follow-up visits per 1000 discharges, $95 \% \mathrm{Cl} 21.1$ to 29.1).

Interpretation: Our study found lower rates of postdischarge follow-up with a medical specialist among older patients and patients with chronic illness who were enrolled in team-based primary care practices compared with those enrolled in traditional primary care practices. Future research is needed to better understand the role of primary health care service organization in improving acute postdischarge care.

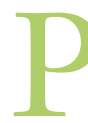
atients admitted to hospital often face gaps in continuity of care, particularly in the period immediately after their discharge, which can place them at high risk of substantial negative health outcomes. ${ }^{1}$ Timely outpatient follow-up after discharge is essential for effective care transition strategies; it represents an opportunity for patients to ask questions about their hospital admission and for physicians to monitor and address problems related to the patient's transition from hospital to community. ${ }^{2-4}$ Patients who receive early outpatient follow-up after discharge from hospital have lower risk of death, unplanned readmission and emergency department visits and account for lower annual expenditures. ${ }^{3,5-11}$ Recognizing the role of follow-up visits in reducing readmissions, the Centers for Medicare and Medicaid Services in the United States introduced new billing codes effective January 2013 for the coordination of postdischarge care, including a face-toface visit within 14 or 7 days after discharge. ${ }^{12}$ For patients in hospital for common causes of admission, such as heart failure, chronic obstructive pulmonary disease and acute myocardial infarction, clinical guidelines recommend that follow-up should occur within 2 weeks or 1 month after discharge., ${ }^{2,6,13-19}$

There is consensus that health systems with high-performing primary care achieve better results on a number of fronts, including better processes of care, better health outcomes and lower overall costs of health care. ${ }^{20}$ Transforming health systems have given rise to a number of innovations in primary

Competing interests: None declared.

This article has been peer reviewed.

Correspondence to: Bruno Riverin, bruno.riverin@mcgill.ca

CMAJ Open 2017. DOI:10.9778/cmajo.20160059 
care delivery that target attributes of primary care such as continuity and coordination of care. Accordingly, since the early 2000s in Canada, jurisdictions have implemented new primary care delivery models designed to facilitate access to continuous and coordinated care across the different levels of care. ${ }^{21-24}$ Family Medicine Groups in Quebec were designed as groups of 6-12 family physicians who work with other health care professionals, primarily 1-2 nurses, to provide primary care to registered patients. The Family Medicine Group policy also supports a broad range of initiatives, including case management, extended hours, practice computerization, regular scheduled appointments, walk-in clinics, home visits, health advice via telephone and emergency on-call services. ${ }^{25}$ Physicians who join a Family Medicine Group maintain the same remuneration schemes as non-Family Medicine Group physicians, which consist predominantly of fee-for-service. Family Medicine Group physicians and non-Family Medicine Group physicians also receive a small financial incentive for each vulnerable patient they register to their practice (i.e., older patients or patients with eligible chronic health conditions). ${ }^{26}$ Nurse specialists, whose salaries are paid by the Ministry of Health and Social Services, are integrated within Family Medicine Group teams and are intended to provide case management, disease prevention and health promotion services. The traditional model in Quebec predominantly consists of solo (or a small group of) physicians who practise independently — without a primary care nurse or support for the aforementioned initiatives.

Evidence is lacking on whether such system-wide innovations in primary care delivery have played a role in improving quality and continuity of care in the period after hospital discharge, in particular for patients with chronic conditions. We sought to describe how rates of timely postdischarge physician follow-up vary by whether older or chronically ill patients are enrolled in new multidisciplinary team-based primary care practices or in traditional primary care practices. We further explored these variations by responsible diagnosis and patient morbidity.

\section{Methods}

\section{Data source}

Data for this analysis included province-wide health insurance claims for inpatient and outpatient services delivered between November 2002 and January 2009 in Quebec. The Régie de l'Assurance Maladie du Québec (RAMQ) pays for health services provided in hospitals and by physicians for all patients registered with Quebec's universal health insurance program. We linked data from the following RAMQ databases using a unique lifetime identifier encrypted from the personal health insurance number: a registered person file, which contains patient demographics; a physician claims file, which contains physician services performed in hospital, office or clinic; a hospital file, which includes information about each hospital admission; and a physician information file, which contains information on the enrolling primary care physician, including practice type and characteristics, number of patients and ser- vices provided, and income source. These RAMQ databases also contain information on the specialty of the billing physician for all physician services. Primary and specialist medical care in Quebec is predominantly funded via fee-for-service payments, with only a small portion of primary care physicians paid in part by salary for services provided within community health centres.

\section{Study setting}

This study is based on a cohort of patients that has been described previously. ${ }^{27,28}$ Patients were selected into this cohort if a primary care physician enrolled them as a "vulnerable patient" between November 2002 and January 2005. Since late 2002, primary care physicians enrol vulnerable patients into their practice by billing a fee code to the RAMQ if a patient is aged 70 years or older or has 1 or more specified chronic health conditions (Appendix 1, available at www.cmajopen.ca/content/5/1/E28/suppl/DC1). ${ }^{26}$ This fee code is available to physicians in both new and traditional primary care practices. We extracted 5 years of health insurance billing data for each patient since the date of their enrolment as vulnerable. We considered 2 analytical samples: hospital admissions for any cause, and hospital admissions for acute myocardial infarction, heart failure and chronic obstructive pulmonary disease, for which timely follow-up care is specifically recommended in clinical guidelines (hereafter referred to as admissions for specific causes). We identified patients admitted for specific causes using International Classification of Diseases, 9th and 10th revisions (ICD-9 and ICD-10) codes for main diagnosis (see Appendix 2, available at www. cmajopen.ca/content/5/1/E28/suppl/DC1). We excluded hospital admissions to long-term care facilities, and those that resulted in a discharge or a transfer to another facility. We further excluded index admissions for mental health and pregnancy or child birth using principal diagnosis codes, same-day readmissions, admissions with in-hospital death, pediatric admissions, admissions with a hospital stay lasting 30 days or more and admissions from Northern Quebec. These represent patient subgroups that likely differ with regards to the patterns of use of and need for primary health care services.

\section{Study design}

We used the index admission as the unit of analysis, which we defined as any hospital admission not preceded by a previous admission in the 30 days before. We assigned exposure depending on whether a patient was enrolled with a physician who practised in a multidisciplinary team-based primary care practice (i.e., a Family Medicine Group) or in a traditional primary care practice on the date of the patient's index admission. The primary analysis examined time to the first outpatient postdischarge follow-up service provided by either a primary care physician or a medical specialist. This was calculated by counting the number of days that had elapsed since the patient was discharged from hospital to the day that any service was billed. Outpatient services include physician services billed in establishments other than the emergency department, including hospital outpatient clinics and office-based practices. In addition, we examined the time to first follow-up with any 
physician. Patients may contribute data for more than 1 index admission and under different exposure levels.

\section{Covariates}

All covariates were measured at the index admission. We included patient age, sex and major diagnostic categories, and the time since enrolment by a primary care physician. We used Quebec's material deprivation index based on the 2006 census dissemination areas as a measure of neighbourhood socioeconomic status, and a categorical variable developed by the Quebec National Institute of Public Health to represent the patient's residential geographic location as a function of the proximity to an urban centre and to a tertiary or secondary referral hospital. We controlled for time since previous use of inpatient care and case-mix adjusted at index admission using 2 variables: patient morbidity level and intensity of hospital resource use. Patient morbidity level is 1 of 3 Resource Utilization Bands (moderate, high or very high morbidity) calculated using the Johns Hopkins Adjusted Clinical Groups Case-Mix System and based on diagnostic codes for both inpatient and outpatient use in the calendar year preceding the index admission. Relative Intensity Weights show the relative use of hospital resources, adjusted for age, comorbidities and complexity level. In addition, we included physician characteristics (age, sex, years in practice, total number of patients and income source) and indicator variables for each hospital as covariates.

\section{Statistical analysis}

We estimated propensity scores from a logistic regression of Family Medicine Group enrolment at index admission on predictors. Covariates and model specifications are listed in Appendix 3 (available at www.cmajopen.ca/content/5/1/E28/ suppl/DC1). We derived stabilized inverse-probability-weights from propensity scores to balance covariates across exposure groups, with standardized differences greater than 10\% considered meaningful. We also used inverse-probability-weights to account for left-censoring of observations that occurred on the day of discharge. Competing risks included death, readmission or emergency department visit because these higher level of care encounters preclude appropriate outpatient postdischarge follow-up. Finally, we estimated adjusted population-averaged rates and rate differences from marginal structural models using the Royston-Parmar flexible parametric model (extended for competing risks) and restricted cubic splines to model the baseline hazard function and time-dependent effects. ${ }^{29,30} \mathrm{We}$ used the clustered bootstrap to obtain $95 \%$ confidence intervals (CIs). We used Stata MP 14 for all analyses.

\section{Results}

The cohort included 351113 older or chronically ill patients admitted to hospital in Quebec for any cause between November 2002 and January 2009, which represented 749537 hospital admissions. Of those admissions, we excluded 128881 (17.2\%) from 106176 patients (Figure 1). The study sample included a total of 620656 index admissions for any cause (312 377 patients), and 90326 admissions for specific causes (57 143 patients). Table 1 shows patient characteristics at admission (characteristics of subsample of patients admitted to hospital for specific causes listed in Appendix 4, available at www.cmajopen.

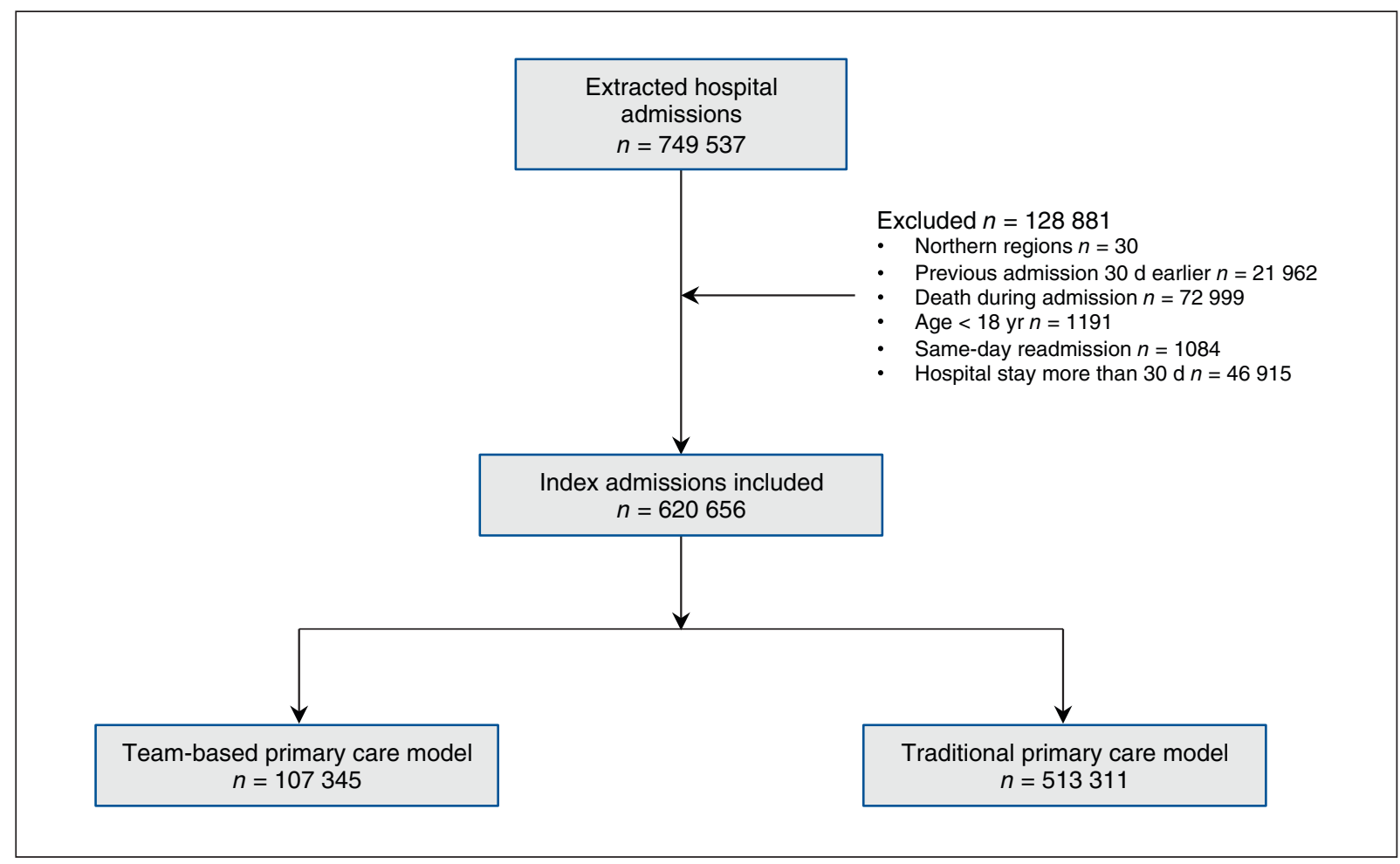

Figure 1: Selection of hospital admissions for the study. 
ca/content/5/1/E28/suppl/DC1). After weighting, there were no standardized differences greater than $10 \%$ between patients in team-based and traditional practices (Table 1; for details on analytical weights see Appendix 5, available at www.cmajopen. ca/content/5/1/E28/suppl/DC1). ${ }^{31,32}$
The unadjusted rates of outpatient physician follow-up visits are shown in Table 2 by primary care delivery model within 7,15 and 30 days of hospital discharge. After adjustment by inverse-probability-weighing, we found no significant differences in the rates of follow-up visit with a primary

\begin{tabular}{|c|c|c|c|c|}
\hline \multirow[b]{2}{*}{ Characteristic } & \multicolumn{2}{|c|}{ Primary care model } & \multicolumn{2}{|c|}{ Absolute standardized difference, \% } \\
\hline & Team-based & Traditional & Before weighting & After weighting \\
\hline $\begin{array}{l}\text { Admissions, no. } \\
(\%)\end{array}$ & $107345(17.3)$ & $513311(82.7)$ & - & - \\
\hline \multicolumn{5}{|l|}{ Sex, no. (\%) } \\
\hline Female & $56568(52.7)$ & $270672(52.7)$ & 0.1 & 1.3 \\
\hline \multicolumn{5}{|l|}{ Age, yr } \\
\hline Mean & 73.3 & 73.3 & 3.8 & 3.2 \\
\hline \multicolumn{5}{|c|}{ Morbidity, no. (\%) } \\
\hline Low-moderate & $19136(17.8)$ & $86812(16.9)$ & 2.4 & 0.0 \\
\hline High & $30677(28.6)$ & $143285(27.9)$ & 1.5 & 0.2 \\
\hline Very high & $57532(53.6)$ & $283214(55.2)$ & 3.2 & 0.2 \\
\hline \multicolumn{5}{|c|}{ Admission cost, Can\$* } \\
\hline Mean & 5656 & 5656 & 1.3 & 0.1 \\
\hline \multicolumn{5}{|c|}{ Length of hospital stay, d } \\
\hline Mean & 7.2 & 7.2 & 4.8 & 0.1 \\
\hline \multicolumn{5}{|c|}{ Time since enrolment with primary care physician, yr } \\
\hline Mean & 2.5 & 2.5 & 16.2 & 0.3 \\
\hline \multicolumn{5}{|c|}{ Year of index admission, no. (\%) } \\
\hline 2002-2003 & $9524(8.9)$ & $81184(15.8)$ & 21.2 & 1.1 \\
\hline 2004 & $19088(17.8)$ & $103224(20.1)$ & 5.9 & 2.2 \\
\hline 2005 & $21317(19.9)$ & $105660(20.6)$ & 1.8 & 1.3 \\
\hline 2006 & $19210(17.9)$ & $95528(18.6)$ & 1.9 & 0.8 \\
\hline 2007 & $18556(17.3)$ & $94428(18.4)$ & 2.9 & 2.8 \\
\hline 2008-2009 & $19650(18.3)$ & $33287(6.5)$ & 31.0 & 0.4 \\
\hline \multicolumn{5}{|c|}{ Material deprivation quintile, $\%$} \\
\hline 1 (low) & $11166(10.4)$ & $71791(14.0)$ & 11.0 & 0.1 \\
\hline 2 & $17142(16.0)$ & $83240(16.2)$ & 0.7 & 0.2 \\
\hline 3 & $22266(20.7)$ & 99303 (19.4) & 3.5 & 1.1 \\
\hline 4 & $25249(23.5)$ & $107648(21.0)$ & 6.1 & 0.1 \\
\hline 5 (high) & $23418(21.8)$ & $116428(22.7)$ & 2.1 & 2.1 \\
\hline Missing & $8104(7.6)$ & $34901(6.8)$ & 2.9 & 1.7 \\
\hline \multicolumn{5}{|c|}{ Geographical region, \% } \\
\hline Urban/university & $24461(22.8)$ & $184971(36.0)$ & 29.4 & 1.8 \\
\hline Suburban & $45359(42.3)$ & $197775(38.5)$ & 7.6 & 0.5 \\
\hline Intermediate & $30301(28.2)$ & $100593(19.6)$ & 20.3 & 0.4 \\
\hline Rural & $7014(6.5)$ & $28277(5.5)$ & 4.3 & 1.8 \\
\hline Missing & $210(0.2)$ & $1695(0.3)$ & 2.6 & 0.3 \\
\hline
\end{tabular}




\section{OPEN}

Research

care physician across primary care models among patients admitted for any cause nor for specific causes (Table 3). Adjusted rates of follow-up with a medical specialist remained significantly lower among patients enrolled in team-based primary care (Table 3). Similar differences in rates of follow-up by a medical specialist were seen among patients admitted to hospital for specific causes. When we considered follow-up with any physician, the difference in rates between primary care delivery models occurred within the first 15 days of discharge, and this difference decreased in the third and fourth weeks postdischarge. Among patients admitted to hospital for specific causes, we did not find significant differences in rates

\begin{tabular}{|c|c|c|c|c|c|c|}
\hline \multirow{3}{*}{$\begin{array}{l}\text { Post- } \\
\text { discharge } \\
\text { outpatient } \\
\text { follow-up }\end{array}$} & \multicolumn{6}{|c|}{ Rate per 1000 discharges } \\
\hline & \multicolumn{3}{|c|}{ Admission for any cause } & \multicolumn{3}{|c|}{ Admission for specific cause } \\
\hline & Team-based & Traditional & Total & Team-based & Traditional & Total \\
\hline \multicolumn{7}{|c|}{ Primary care physician } \\
\hline Within $7 \mathrm{~d}$ & 106.3 & 118.5 & 116.4 & 119.4 & 130.5 & 128.5 \\
\hline Within $15 \mathrm{~d}$ & 205.2 & 223.2 & 233.8 & 246.1 & 267.1 & 263.4 \\
\hline Within $30 \mathrm{~d}$ & 355.4 & 377.5 & 373.7 & 399.8 & 416.8 & 413.9 \\
\hline \multicolumn{7}{|c|}{ Medical specialist } \\
\hline Within $7 \mathrm{~d}$ & 126.0 & 145.0 & 141.7 & 85.2 & 99.4 & 97.0 \\
\hline Within $15 \mathrm{~d}$ & 247.6 & 276.8 & 271.8 & 175.0 & 196.5 & 192.9 \\
\hline Within $30 \mathrm{~d}$ & 397.6 & 427.6 & 422.4 & 299.3 & 321.6 & 317.9 \\
\hline \multicolumn{7}{|c|}{ Any physician } \\
\hline Within $7 \mathrm{~d}$ & 228.2 & 257.4 & 252.4 & 212.7 & 224.6 & 222.6 \\
\hline Within $15 \mathrm{~d}$ & 420.6 & 468.9 & 462.3 & 415.8 & 428.2 & 426.1 \\
\hline Within $30 \mathrm{~d}$ & 649.4 & 681.9 & 676.2 & 645.9 & 644.8 & 645.0 \\
\hline
\end{tabular}

\begin{tabular}{|c|c|c|}
\hline \multirow{2}{*}{$\begin{array}{l}\text { Postdischarge outpatient } \\
\text { follow-up }\end{array}$} & \multicolumn{2}{|c|}{ Rate per 1000 discharges $(95 \% \mathrm{Cl}) \dagger$} \\
\hline & Admission for any cause & Admission for specific cause \\
\hline \multicolumn{3}{|l|}{ Primary care physician } \\
\hline Within $7 \mathrm{~d}$ & $-0.7(-2.1$ to 3.6$)$ & $1.9(-6.5$ to 10.5$)$ \\
\hline Within $15 d$ & $1.6(-2.3$ to 5.5$)$ & $0.6(-10.6$ to 11.8$)$ \\
\hline Within $30 \mathrm{~d}$ & $1.7(-6.3$ to 3.0$)$ & $6.2(-7.1$ to 19.5$)$ \\
\hline \multicolumn{3}{|l|}{ Medical specialist } \\
\hline Within $7 d$ & $-16.9(-19.9$ to -13.9$)$ & $-13.7(-19.9$ to -7.5$)$ \\
\hline Within $15 \mathrm{~d}$ & $-25.1(-29.1$ to -21.1$)$ & $-20.7(-29.2$ to -12.2$)$ \\
\hline Within $30 \mathrm{~d}$ & $-25.0(-29.7$ to -20.4$)$ & $-21.4(-32.1$ to -10.8$)$ \\
\hline \multicolumn{3}{|l|}{ Any physician } \\
\hline Within $7 \mathrm{~d}$ & $-16.1(-19.9$ to -12.3$)$ & $-11.9(-21.8$ to -2.0$)$ \\
\hline Within $15 \mathrm{~d}$ & $-18.2(-22.7$ to -13.7$)$ & $-12.4(-24.2$ to -0.5$)$ \\
\hline Within $30 \mathrm{~d}$ & $-13.5(-17.9$ to -9.1$)$ & $1.1(-10.5$ to 12.8$)$ \\
\hline \multicolumn{3}{|c|}{$\begin{array}{l}\text { Note: } \mathrm{Cl}=\text { confidence interval. } \\
{ }^{*} \text { All discharges }(n=620656 \text { ) were included in the analysis. Adjusted for age, sex, time since enrolment with a primary care } \\
\text { physician, geographical location, material and social deprivation quintile, resource utilization band, major diagnostic group, } \\
\text { length of stay in hospital, relative intensity weight, number of previous admissions, time since previous discharge, } \\
\text { characteristics of enrolling physician (sex, years in practice, income source, total number of patients), calendar year and } \\
\text { hospital (see Appendix 4). } \\
\text { †Clustered bootstrap } 95 \% \mathrm{Cls.}\end{array}$} \\
\hline
\end{tabular}


of follow-up by any physician at 30 days postdischarge owing to limited precision and wider CIs (Table 3).

In Figure 2, we present the difference in rates of primary care physician follow-up visits between primary care delivery models by subgroup of patient morbidity level. We found that among patients with a very high level of morbidity, those enrolled in team-based primary care practices were more likely to receive timely follow-up with a primary care physician. This represents more than 10 additional patients enrolled in teambased primary care receiving follow-up by a primary care physician within 30 days for every 1000 discharges. On the contrary, among patients with moderate or high morbidity, those enrolled in team-based practices were less likely to receive timely follow-up by a primary care physician. Rate differences for follow-up visits with a medical specialist did not vary by morbidity level.

\section{Interpretation}

Our analysis of more than 600000 discharges that occurred between 2002 and 2009 in Quebec showed differences in timely outpatient care in the postdischarge period for patients enrolled in multidisciplinary team-based primary care practices compared with those enrolled in traditional primary care practices. Overall, patients enrolled in team-based primary care had similar rates of follow-up visits by a primary care physician, but significantly lower rates of follow-up with a medical specialist. Among patients with the highest level of morbidity, multidisciplinary team-based primary care practices were associated with higher rates of timely follow-up with a primary care physician, suggesting that these widely implemented innovations in primary care delivery may have achieved better results in the coordination of postdischarge care for the heaviest users of the health care system. In addition, we found that 1 in 3 older or chronically ill patients admitted to hospital for acute myocardial infarction, heart failure or chronic obstructive pulmonary disease did not receive physician follow-up care within 30 days of discharge, excluding patients seen in the emergency department or seen by other health care professionals. This is considerably less than what was reported in other Canadian jurisdictions, where the most patients $(77 \%-92 \%)$ saw a physician within a month of discharge.

Enrolment in multidisciplinary team-based primary care models at index admission was associated with lower rates of follow-up visits with a medical specialist in the month after discharge. Elsewhere, we report better postdischarge outcomes associated with enrolment in team-based primary care for the most medically complex patients (lower rates of postdischarge visits to the emergency department, lower rates of postdischarge death and similar readmission rates). ${ }^{33}$ In this context, we think it is unlikely that the lower rates of follow-up with a medical specialist suggest lesser quality of care in team-based primary care models. We hypothesize that allied health professionals in multidisciplinary teams have substituted for a portion of the needed follow-up care after hospital discharge for patients with very high morbidity. Alternative explanations are also plausible but difficult to test empirically in our context. For example, physicians in team-based primary care models may provide more comprehensive postdischarge follow-up, and their patients may have less need for a medical specialist followup. Future research is needed to investigate such explanations

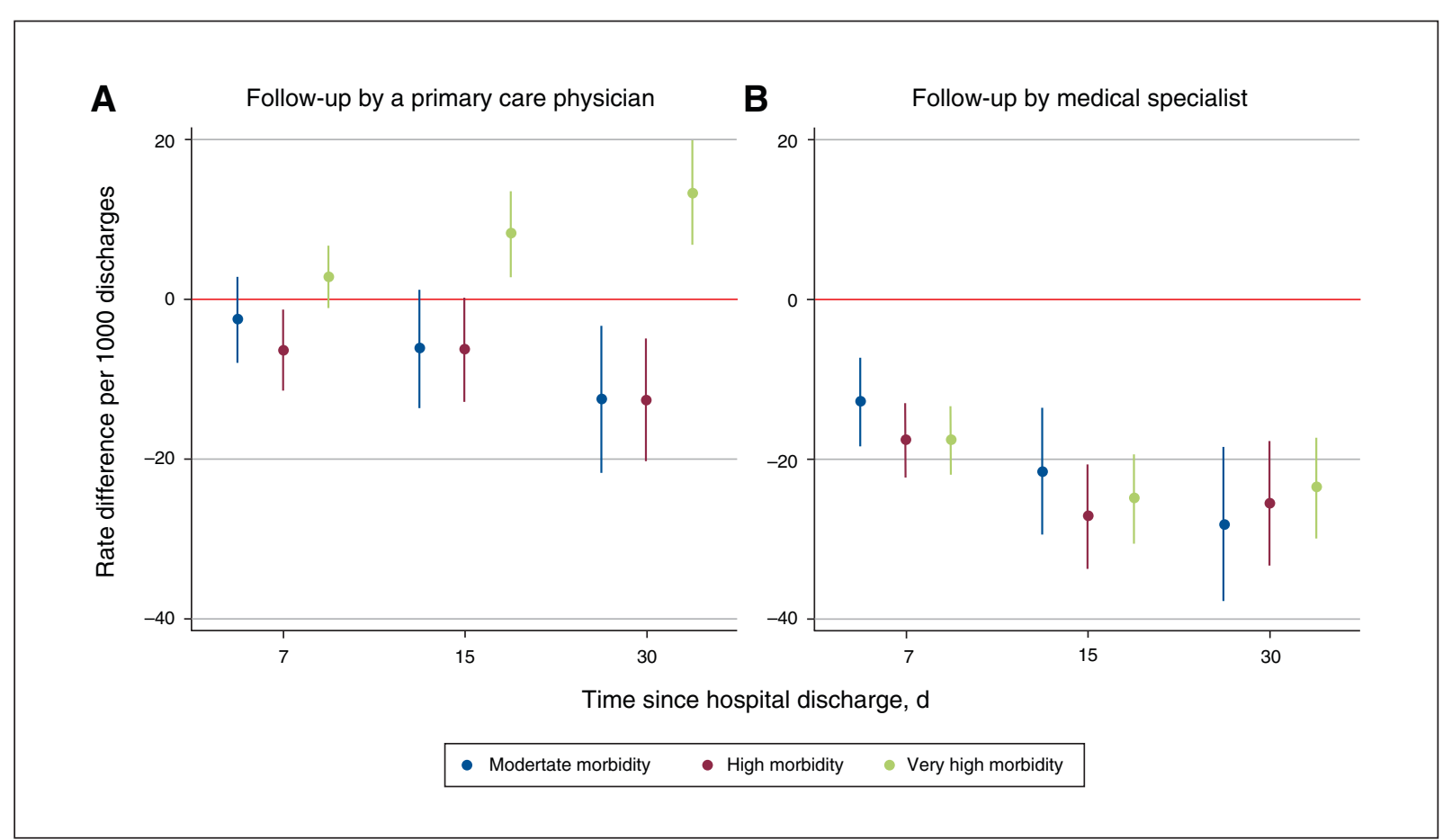

Figure 2: Adjusted difference in rates of postdischarge outpatient follow-up between multidisciplinary team-based and traditional primary care practices, by physician type and level of morbidity. 
to assess whether team-based primary care practices are in fact providing more appropriate (and potentially less expensive) care to patients when they are discharged from hospital.

\section{Limitations}

The interpretation of our study's findings is limited by the lack of data on nurses (or other allied health professionals) practising in primary care teams, which prevents us from providing a complete portrait of how team-based primary care delivery models are performing on outpatient follow-up visits in the postdischarge period compared with traditional primary care practices.

Data on visits with nurses are not available in Quebec billing data because nurses are paid a salary and do not bill per service for the care they provide. By 2010, most Family Medicine Groups had 1 or more nurses within their team; this was not the case for traditional primary care practices. The roles and tasks of nurses described in the supporting Family Medicine Group policy documents include systematic follow-up and case management for patients with complex medical needs; ${ }^{34}$ for this reason, some substitution by nurses for family doctors in the postdischarge period may have occurred, and follow-up by nurses may have (directly or indirectly) replaced some share of the fewer visits to a medical specialist occurring within 30 days of hospital discharge among Family Medicine Group patients. This reallocation of human resources is desirable after organizational reforms in primary care.

We were further limited by the fact that administrative health databases lack information on patients' functional status and direct measures of severity of their conditions. Despite our adjustment efforts, unmeasured differences in case-mix across primary care delivery models are still possible. Our results show that the differences in rates of primary care physician follow-up between primary care models were reduced after adjustment for measured covariates, which leads us to believe that our estimates may have been too conservative if residual differences in case-mix exist (e.g., patients enrolled in team-based primary care practices are healthier and have fewer functional limitations). In contrast, covariate adjustment did not reduce the difference in rates of follow-up with a medical specialist between primary care delivery models nearly as much, which provides some evidence that residual confounding is not a major issue for estimates on this outcome. Furthermore, there is always a possibility of selection bias because physician participation and patient enrolment in primary care models depends largely on physician preferences and characteristics. ${ }^{27} \mathrm{We}$ included measured characteristics on both treating primary care physicians and patients in the derivation of propensity scores, which likely account for part but not all of this selection bias. In addition, we designed this analysis to specifically examine timeliness of follow-up care after discharge; in doing so, we did not examine the volume of services or the comprehensiveness or appropriateness of care after discharge.

Finally, we used data for the period between 2002 and 2010; timely access to more recent data in Quebec is essential to assess the current performance of Family Medicine Groups.

\section{Conclusion}

Seeing a doctor shortly after hospital discharge is usually recommended. Our results suggest that system-wide innovations in primary care delivery that consist of multidisciplinary teambased practices were associated with similar rates of follow-up with a primary care physician, and with lower rates of follow-up with a medical specialist, particularly within the first 2 weeks of hospital discharge, compared with traditional practices.

Our overall results masked heterogeneous associations across levels of patient morbidity, whereby the most medically complex patients received more follow-up with a primary care physician if they were enrolled in team-based primary care practices, whereas less complex patients did not. This may suggest that new team-based primary care models perform better on this process of care measure for patients with the highest level of morbidity. Furthermore, nurses practising in primary care teams likely provide some of the timely postdischarge follow-up care, and it is critical that future research empirically test this hypothesis to assess its validity and to best inform future strategies to improve patient- and system-level outcomes in the postdischarge period, including reducing readmissions and emergency department visits. Lastly, given that outpatient postdischarge follow-up may help reduce hospital readmissions and mortality, future research and policies should work toward new ways to improve rates of timely follow-up. This may include targeting innovations and additional resources in team-based primary care delivery, such as computerization, and the role played by nurses in postdischarge follow-up.

\section{References}

1. Dharmarajan K, Hsieh AF, Kulkarni VT, et al. Trajectories of risk after hospitalization for heart failure, acute myocardial infarction, or pneumonia: retrospective cohort study. BM7 2015;350:h411.

2. Physician follow-up after hospital discharge: progress in meeting best practices. Ottawa: Canadian Institute of Health Information; 2015. Available: https://secure. cihi.ca/free_products/Physician-Follow-Up-Study-mar2015_EN.pdf (accessed 2016 Mar. 1).

3. Brooke BS, Stone DH, Cronenwett JL, et al. Early primary care provider follow-up and readmission after high-risk surgery. FAMA Surg 2014; 149:821-8.

4. Sommers A, Cunningham PJ. Physician visits after hospital discharge: implications for reducing readmissions. National Institute for Health Care Reform (NIHCR); 2011.

5. Hernandez AF, Greiner MA, Fonarow GC, et al. Relationship between early physician follow-up and 30-day readmission among Medicare beneficiaries hospitalized for heart failure. $7 A M A$ 2010;303:1716-22

6. Jackson C, Shahsahebi M, Wedlake T, et al. Timeliness of outpatient followup: an evidence-based approach for planning after hospital discharge. Ann Fam Med 2015;13:115-22.

7. Lin CY, Barnato AE, Degenholtz HB. Physician follow-up visits after acute care hospitalization for elderly Medicare beneficiaries discharged to noninstitutional settings. 7 Am Geriatr Soc 2011;59:1947-54.

8. McAlister FA, Youngson E, Bakal JA, et al. Impact of physician continuity on death or urgent readmission after discharge among patients with heart failure. CMA7 2013;185:E681-9.

9. Misky GJ, Wald HL, Coleman EA. Post-hospitalization transitions: Examining the effects of timing of primary care provider follow-up. 7 Hosp Med 2010; 5:392-7.

10. Sharma G, Kuo YF, Freeman JL, et al. Outpatient follow-up visit and 30-day emergency department visit and readmission in patients hospitalized for chronic obstructive pulmonary disease. Arch Intern Med 2010;170:1664-70.

11. Ezekowitz JA, van Walraven C, McAlister FA, et al. Impact of specialist follow-up in outpatients with congestive heart failure. CMA7 2005;172:189-94.

12. 2013 Medicare physician fee schedule. Baltimore: Centers for Medicare and Medicaid Services; 2013.

13. Howlett JG, McKelvie RS, Costigan J, et al. The 2010 Canadian Cardiovascular Society guidelines for the diagnosis and management of heart failure 
update: heart failure in ethnic minority populations, heart failure and pregnancy, disease management, and quality improvement/assurance programs. Can 7 Cardiol 2010;26:185-202.

14. Tu JV, Khalid L, Donovan LR, et al.; Canadian Cardiovascular Outcomes Research Team/Canadian Cardiovascular Society Acute Myocardial Infarction Quality Indicator Panel. Indicators of quality of care for patients with acute myocardial infarction. CMA7 2008;179:909-15.

15. Tran CT, Lee DS, Flintoft VF, et al.; Canadian Cardiovascular Outcomes Research Team/Canadian Cardiovascular Society. Acute Myocardial Infarction Quality Indicator Panel CCORT/CCS quality indicators for acute myocardial infarction care. Can 7 Cardiol 2003;19:38-45.

16. Abramson M, Crockett AJ, Dabscheck E, et al. The COPDX Plan: Australian and New Zealand Guidelines for the management of chronic obstructive pulmonary disease 2014. Milton (Australia): Lung Foundation Australia and Thoracic Society of Australia; 2014. Available: http://copdx.org.au/wp-content/ uploads/2011/08/COPDX-V2.39-October-2014_FINAL.pdf (accessed 2016 Mar. 22).

17. Lee DS, Tran C, Flintoft $\mathrm{V}$, et al. Canadian Cardiovascular Outcomes Research Team/Canadian Cardiovascular Society Heart Failure Quality Indicator Panel. CCORT/CCS quality indicators for congestive heart failure care. Can 7 Cardiol 2003;19:357-64.

18. Côté G. Traitement de la MPOC. Rimouski (QC): Centre intégré de santé et de services sociaux du Bas St-Laurent; 2011. Available: www.chrr.qc.ca/professionnelle /guide/pdf/autres/mpoc.pdf (accessed 2016 Mar. 22).

19. Quality-based procedures: clinical handbook for chronic obstructive pulmonary disease (acute and postacute). Toronto: Health Quality Ontario and Ministry of Health and LongTerm Care; 2015. Available: www.hqontario.ca/Portals/0/Documents/evidence/ clinical-handbooks/copd-integrated-03022015-en.pdf (accessed 2016 Apr. 2).

20. Starfield B. The future of primary care: refocusing the system. $N$ Engl $7 \mathrm{Med}$ 2008;359:2087, 2091.

21. Clair M. Les solutions émergentes - Rapport et recommandations [report]. Commission d'étude sur les services de santé et les services sociaux. In: Gouvernement du Québec, editor. 2000;410.

22. Hutchison B, Levesque JF, Strumpf E, et al. Primary health care in Canada: systems in motion. Milbank Q 2011;89:256-88.

23. Kirby MJL. The health of Canadians - the federal Role. Final report, Volume 6: recommendations for reform. Ottawa: Parliament of Canada, October 2002. Available: www.parl.gc.ca/37/2/parlbus/commbus/senate/com-e/soci-e/rep-e/ repoct02vol6-e.htm (accessed 2016 Mar. 1).

24. Romanow RJ. Building on values: the future of bealth care in Canada - Final report. Ottawa: Public Works and Government Services Canada; 2002 Available: http://dsp-psd.pwgsc.gc.ca/Collection/CP32-85-2002E.pdf (accessed 2016 Apr. 2)

25. Groupe de médecine de famille (GMF). Québec (Que): Ministère de la Santé et des Services Sociaux; 2016. Available: www.sante.gouv.qc.ca/systeme-sante-en -bref/groupe-de-medecine-de-famille-gmf/ (accessed 2016 Aug. 8).

26. Groupe de médecine de famille (GMF) - Entente particulière provisoire/Prise en charge et suivi des clientèles vulnérables. Amendement no 95. Québec: Régie de l'assurance maladie du Québec; 2006;33-1. Available: www.ramq.gouv.qc.ca/ SiteCollectionDocuments/professionnels/manuels/104-brochure-1-omnipraticiens /007_enten_particu_entente_omni.pdf (accessed 2016 Mar. 1).

27. Coyle N, Strumpf E, Fiset-Laniel J, et al. Characteristics of physicians and patients who join team-based primary care practices: evidence from Quebec's Family Medicine Groups. Health Policy 2014;116:264-72.

28. Héroux J, Moodie EE, Strumpf E, et al. Marginal structural models for skewed outcomes: identifying causal relationships in health care utilization. Stat Med 2014;33:1205-21.
29. Lambert PC. Extending the flexible parametric survival model for competing risks. Stata 7 2013;13:344-55.

30. Royston P, Lambert PC. Flexible parametric survival analysis using Stata: beyond the Cox model. College Station (TX): Stata Press; 2011.

31. Cole SR, Hernan MA. Constructing inverse probability weights for marginal structural models. Am 7 Epidemiol 2008;168:656-64.

32. Austin PC, Stuart EA. Moving towards best practice when using inverse probability of treatment weighting (IPTW) using the propensity score to estimate causal treatment effects in observational studies. Stat Med 2015;34:3661-79.

33. Riverin BD, Strumpf E, Naimi AI, et al. Readmission, post-discharge emergency department visits and mortality in the context of Canadian primary care innovations. CMA7. In press.

34. Rapport du groupe de travail OIIQ/FMOQ sur les rôles de l'infirmière et du médecin omnipraticien de première ligne et les activités partageables. Montréal: Ordre des infirmières et infirmiers du Québec, and Fédération des médecins omnipraticiens du Québec; 2005. Available: www.oiiq.org/sites/default/ files/uploads/pdf/FAQ/oiiq_fmoq.pdf (accessed 2016 Apr. 2).

Affiliations: Department of Epidemiology (Riverin, Li, Diop, Strumpf), Biostatistics \& Occupational Health, McGill University; Department of Pediatrics (Riverin, Li), Montreal Children's Hospital, McGill University Health Centre, Montréal, Que.; Department of Epidemiology (Naimi), University of Pittsburgh Graduate School of Public Health, Pittsburgh, Penn.; Direction de la santé publique du CIUSS du Centre-Sud-de-l'Ilede-Montréal (Diop, Provost, Strumpf); Centre de recherche du Centre Hospitalier de l'Université de Montréal (Provost); Institut de recherche en santé publique de l'Université de Montréal (Strumpf); Department of Economics (Strumpf), McGill University, Montréal, Que.

Contributors: All six authors (Bruno Riverin, Patricia Li, Ashley Naimi, Mamadou Diop, Sylvie Provost, and Erin Strumpf) are responsible for the reported research. All authors have participated in the concept and design of this research, in the analysis and interpretation of the data, in the drafting or revising of the manuscript and approval of the version to be published. All of the authors have agreed to act as guarantors of the work.

Funding: Bruno Riverin is funded by the Fonds de recherche du Québec - Santé - Unité SUPPORT du Québec and by a Partnership for Health Systems Improvement grant from the Canadian Institutes of Health Research. Patricia Li was funded by a Chercheur-boursier clinicien Junior 1 from the Fonds de la Recherche du Québec - Santé and the Ministère de la Santé et des Services sociaux du Québec and a New Investigator Salary Award from the Canadian Institutes of Health Research. Erin Strumpf was funded by a Chercheur-boursier Junior 1 from the Fonds de la Recherche du Québec - Santé and the Ministère de la Santé et des Services sociaux du Québec.

Prior presentations: Academy Health 2016 Annual Research Meeting, June 26-28, Boston; 2016 Epidemiology Congress of the Americas, June 21-24, Miami.

Supplemental information: For reviewer comments and the original submission of this manuscript, please see www.cmajopen.ca/content/5/1/ E28/suppl/DC1 